\title{
Políticas públicas e estratégias territoriais de implementação: uma análise do desenho institucional dos CONSADS no Brasil
}

\author{
Sandro Pereira Silva ${ }^{1}$
}

\section{RESUMO}

O presente artigo visou analisar o processo de concepção e implementação dos Consórcios de Segurança Alimentar e Desenvolvimento Local (CONSADs) no Brasil, no intuito de identificar quais as principais inovações institucionais no campo das políticas públicas com base em uma abordagem territorial, bem como os entraves para sua operacionalização. Os CONSADs foram implementados inicialmente em 2003 no âmbito de uma estratégia maior de combate à fome, miséria e para o estímulo ao desenvolvimento local, que era o Programa Fome Zero. Seu objetivo era constituir arranjos federativos envolvendo municípios com altos índices de pobreza para serem apoiados com diversos programas governamentais, no intuito de dinamizar novas oportunidades de negócio para a dinamização das economias internas. A estratégia dos CONSADs apresentou importantes inovações no campo normativo para a análise de implementação de políticas públicas no Brasil. No entanto, alguns entraves operacionais ficaram evidentes na implementação desse programa.

Palavras-chave: políticas públicas; desenvolvimento local; abordagem territorial; programas intersetoriais; coordenação federativa.

Public policies and territorial implementation strategies: an analysis of institutional design in Brazilian CONSADs

\begin{abstract}
This paper aimed to analyze the process of design and implementation of Consortium for Food Security and Local Development (CONSADs) in Brazil in order to identify the main institutional innovations in the field of public policies based on a territorial approach, as well as barriers for its operation. The CONSADs were implemented in 2003 as part of a larger strategy for combating hunger, poverty and stimulating local development, which was the Zero Hunger Program. His goal was to provide federative arrangements involving municipalities with high poverty rates to be supported with various government programs in order to stimulate new business opportunities to stimulate local economies. The strategy of CONSADs introduced important innovations in the legal field to the analysis of the implementation of public policies in Brazil. However, some operational barriers were evident in the implementation of this program.
\end{abstract}

Keywords: public policies; local development; territorial approach; intersectoral programs; federal coordination.

\section{INTRODUÇÃO}

Como resultado do conjunto de transformações no cenário político-institucional brasileiro recente, sobretudo após a redemocratização e a nova Constituição Federal nos anos

\footnotetext{
${ }^{1}$ Economista, Mestre em Economia (UFV). Doutorando em Políticas Públicas e Estratégias de Desenvolvimento (IE/UFRJ). Técnico do Instituto de Pesquisa Econômica Aplicada (IPEA/DF).
} 
1980, a sociedade civil passou a ter ao seu alcance novos mecanismos de participação que lhe permitiram levar até as diferentes esferas do poder público suas demandas, muitas vezes organizadas no plano local, para serem consideradas nas políticas nacionais. Com isso, além da exigência de políticas públicas efetivas aliadas à garantia de controles democráticos, novas estratégias de planejamento e coordenação da ação governamental também passaram a ser demandadas.

Paralelamente, o conceito de território passou a figurar de forma recorrente em várias estratégias de ação governamental, em todos os níveis federativos. De maneira geral, o termo território tem sido utilizado em diferentes programas para identificar espaços geográficos específicos, caracterizado por uma realidade socioeconômica que envolve demandas e potencialidades próprias. Com isso, os gestores buscam estabelecer mecanismos diferenciados de intervenção que estejam em maior consonância com as realidades locais, marcadas por um cenário de extremas desigualdades entre elas, e que interaja positivamente com a atividade de diversos atores sociais (públicos e privados) que já atuam em diferentes setores nesses territórios. Essa estratégia, conhecida na literatura como abordagem territorial ou territórios de incidência de políticas públicas (SILVA, 2013), se difere dos antigos projetos e planos de desenvolvimento regional justamente pelo fato de estabelecer uma relação diferenciada entre Estado e sociedade, permitindo maior participação dos atores locais na definição das prioridades e no acompanhamento das ações que incidem sobre seus territórios.

Um dos programas recentes no âmbito do governo federal que se utilizou dessa abordagem territorial é o caso dos Consórcios de Segurança Alimentar e Desenvolvimento Local (CONSADs), instituído em 2003, no âmbito do programa Fome Zero. Os CONSADs foram planejados enquanto territórios institucionalizados, compostos por municípios que possuem grande contingente do público a ser envolvido no programa Fome Zero e que necessitam de maior apoio em termos de investimentos em pequenos projetos produtivos para a dinamização de economia e a geração local de emprego e renda.

Dada essa contextualização inicial, o presente artigo visou analisar o processo de concepção e implementação dos CONSADs no Brasil, no intuito de identificar quais as principais inovações institucionais no campo das políticas públicas que sua estratégia trouxe, bem como os entraves para sua operacionalização no território nacional. Para isso, este trabalho está dividido em quatro seções, incluindo essa introdução. Na seção dois são debatidos alguns aspectos importantes para as análises aqui propostas envolvendo Estado, território e planejamento de políticas públicas. Na seção três são apresentados os objetivos e 
toda a discussão em torno da estratégia dos CONSADs. Por fim, são tecidas algumas considerações conclusivas sobre o trabalho.

\section{ESTADO, TERRITÓRIO E POLÍTICAS PÚBLICAS}

Os anos finais do século XX foram de grandes transformações políticas econômicas a nível global em virtude do período conturbado pelo qual atravessava o capitalismo global desde o fim dos anos 1970. Tais transformações levaram a uma reorientação na forma de atuação do Estado brasileiro, acarretando em maior abertura e desregulamentação da economia, privatização de diversas empresas estatais, maior rigor no ajuste fiscal com vistas ao controle da dívida pública, entre outros fatores que caracterizaram um ajuste de natureza neoliberal nas estruturas de Estado, comprometendo fortemente sua capacidade de planejamento e intervenção na trajetória de desenvolvimento.

Por outro lado, o país vinha de um recente processo de redemocratização e fortalecimento de diversos grupos sociais, que passaram a ter maior liberdade de organização e mobilização em busca do reconhecimento de direitos básicos de cidadania. Parte importante dessas novas demandas sociais foram consolidadas institucionalmente com a promulgação da Constituição Federal de 1988, que inclusive recebeu a alcunha informal de "Constituição Cidadã". Com ela, o Estado passou a ser responsabilizado por uma série de novos investimentos e garantias sociais.

Esses dois processos são, como se pode observar, claramente antagônicos, opondo a necessidade de um Estado mais enxuto e menos interventor de um lado, e de outro, um Estado com maior responsabilidade de investimentos e regulação das relações sociais. Tal impasse tornou bem mais complexo o processo de determinação da agenda governamental, com a atuação de diferentes grupos sociais e corporativos buscando influenciar as decisões políticas dos planejadores.

No caso das políticas sociais esse processo é bem elucidativo. O aumento das demandas sociais e a regulamentação dos novos direitos garantidos constitucionalmente obrigaram o Estado brasileiro a se reestruturar de modo a dar respostas à sociedade, sujeito ao escrutínio eleitoral. Após uma série de planos econômicos mal sucedidos e de um cenário de instabilidade econômica e política a partir do final dos anos 1980, a segunda metade da década de 1990 trouxe uma nova perspectiva para o planejamento econômico, após a relativa estabilização econômica alcançada com o Plano Real, implementado no final do governo 
Itamar Franco em 1994, mesmo sendo consolidado à custa de contenção da atividade econômica (sobretudo via taxa de juros elevada), vulnerabilidade das contas externas e aumento da dívida pública.

Paralelamente ao período de ajuste macroeconômico, o primeiro governo do presidente Fernando Henrique Cardoso (1995/1998) iniciou um processo de reforma do Estado, aos moldes da chamada New Public Management, que havia sido levada a cabo em vários países na década anterior, tais como Inglaterra, Austrália e Nova Zelândia, e passava então a ser assumida nos países "em desenvolvimento", como Chile, Argentina e México, sob assessoria de organismos internacionais, a exemplo do Banco Mundial, o Fundo Monetário Internacional (FMI) e o Banco Interamericano de Desenvolvimento (BID). No plano da gestão, essas reformas visavam, entre outros fatores, dar uma nova dinâmica de atuação do Estado nas políticas sociais, na qual passou-se a utilizar a ideia de "serviços públicos nãoestatais", que se referiam a uma série de políticas que podiam ser ofertadas de maneira descentralizada, em parceria com organizações de direito privado que competiriam entre si pelo financiamento Estado, com a garantia da participação e monitoramento das organizações da sociedade civil na sua implementação (accountability). Essa seria uma forma de desresponsabilizar o Estado na condução de políticas universais, dando ênfase à focalização das ações e investimentos públicos, e deixando ao mercado a tarefa de suprir serviços públicos complementares.

Paralelamente à imposição desse novo modelo de organização do Estado, outra noção que passou a ganhar espaço no meio acadêmico e político-institucional no final dos anos 1990 foi o conceito de território. A apropriação deste conceito, bem como o entendimento das dimensões que ele abrange (patrimônio natural, identidade local, composição do tecido social etc.) para fins de definição da agenda governamental, acarretou o surgimento de diversos programas nos últimos anos, nas mais diferentes estruturas de governo, que se reportam ao território para justificar a adoção de um novo programa ou uma metodologia de intervenção. Esta nova estratégia de ação pública passou a ser denominada abordagem territorial do desenvolvimento.

Segundo Silva (2013), a abordagem territorial, da forma como vem sendo anunciada, almeja designar um novo paradigma para o planejamento de políticas públicas nacionais no Brasil, que se distinga dos antigos instrumentos de planejamento adotados por um Estado centralizador e autoritário. O autor apresentou uma definição sintética de território geralmente utilizada nos marcos normativos dos programas governamentais como sendo: 
[...] uma base flexível sobre a qual agem distintas forças endógenas e exógenas, de maneira que ele se encontra continuamente submetido a relações de poder - conflitivas ou cooperativas nos processos históricos de apropriação e dominação do território, bem como a pressões por mudanças, que podem implicar expansão ou deslocamento. O território é, portanto, a expressão concreta das múltiplas dimensões das interações sociais (econômicas, políticas, simbólicas), plasmada sob um determinado recorte espacial.

No entanto, a apropriação deste conceito enquanto instrumento operacional para as políticas governamentais ainda se encontra difusa, carecendo de novas análises empíricas dos programas que fazem uso dessa abordagem. Trata-se então de buscar elementos analíticos que auxiliem na compreensão dos avanços e das controvérsias na condução desse novo paradigma de intervenção estatal, com seus métodos, instrumentos e procedimentos.

Segundo Bertone e Mello (2006, p. 140), uma política ancorada na abordagem territorial "depende da clareza de conceitos, objetivos, funções e mecanismos operacionais". Porém, há uma série de dificuldades teórico-metodológicas comuns na formulação de políticas desta natureza, de maneira que sua implementação requer atenção especial por parte de seus formuladores. As dificuldades no entendimento dos autores são: $i$ ) a escolha da base geográfica como unidade territorial (bacia hidrográfica, ecossistema, bioma ou município, cidade, região); ii) a definição de escala de intervenção (macrorregional, sub-regional, local); iii) o grau de detalhamento das informações e sua integração à base geográfica; iv) a adequação das informações à escala definida; e v) a adoção de método de negociação com os atores.

O enfrentamento dessas dificuldades exige o estabelecimento de constantes canais de diálogos entre poder público, empresas e organizações sociais, que são os atores principais envolvidos na dinâmica local. Ou seja, as diversas possibilidades de constituição de uma estratégia territorial de intervenção requerem distintas articulações institucionais e organizacionais de governança que garantem sua operacionalização mais efetiva nas configurações territoriais a serem consideradas. Tais arranjos terão maior complexidade à medida que envolva um conjunto mais denso de estruturas de poder social e político ministérios, secretarias de estado, prefeituras, sindicatos, empresas ou associações empresariais, igrejas, lideranças comunitárias etc. (SILVA, 2013). Isto exigirá dos atores interessados - públicos e privados - maior "habilidade social” (FLIGSTEIN, 2007) para induzir comportamentos cooperativos interorganizacionais para uma possível consolidação de projetos que envolvam lideranças de diferentes grupos sociais e que, com isto, permitam alcançar os resultados previamente almejados.

A abordagem territorial vem sendo crescentemente adotada no intuito de se estabelecer uma estratégia de coordenação mais eficiente das políticas públicas nacionais, 
englobando os princípios da descentralização administrativa e da participação popular. As ações governamentais de planejamento territorial se fundamentam a partir de uma crítica ao modelo tradicional de políticas públicas no país, ao substituírem o enfoque municipalista, de gestão autocrática ou centralista, por uma atuação intermunicipal, legitimada pelos agentes sociais locais. De maneira geral, seus desenhos normativos buscam articular, com vistas à maior incidência territorial das políticas públicas, as seguintes dimensões: i) política: capacidades, competências e interesses para a governança territorial e a gestão de conflitos; ii) sociocultural: identidade e coesão social que facilitem as ações coletivas; e iii) econômica: desenvolvimento e superação dos patamares de pobreza e desigualdade.

Com a definição de territórios de atuação e intervenção pública, envolvendo grupos com diferentes entes federativos, o planejamento governamental tem a seu favor uma série de fatores, uma vez que permite: definir áreas ou regiões de intervenção com base em indicadores sociais, geográficos ou outros critérios técnicos, de acordo com a natureza e o objetivo de cada política específica; diminuir significativamente o número de interlocutores a que o órgão central responsável tem de se remeter para a implementação das ações; obter diagnósticos mais precisos sobre a infraestrutura e os recursos humanos necessários para a otimização da política; mapear grupos sociais e forças políticas presentes em cada contexto territorial com potencial para contribuir na implementação da política; e construir um arranjo institucional que propicie um maior grau de conectividade com outras políticas públicas que também incidam sobre tais territórios (SILVA, 2013b).

Chama-se a atenção também para a necessidade de um cuidado especial na definição de territórios que encerram em seu espaço diferentes naturezas de desigualdade. Os limites socioeconômicos, simbólicos e políticos dos territórios, como lembrou Milani (2008), são obstáculos relevantes à participação, podendo inclusive aprofundar a desigualdade política no âmbito dos próprios dispositivos participativos. Nesse caso, o território pode ser apoderado por grupos dominantes e servir como instrumento de um aprofundamento consentido da desigualdade, fazendo-se valer da prerrogativa da participação social e da autonomia local. Isso porque, ao definirem-se contextos territoriais específicos, delimitam-se também áreas de disputas e conflitos que não podem ser negligenciados em um processo de elaboração e implementação de políticas públicas. Como resultado, diferentes segmentos sociais locais não conseguem ser representados nas instâncias deliberativas dos programas passam a ser invisibilizados pelos grupos mais organizados que comandam as definições nos territórios. 
A temática territorial permitiu ainda a emergência, na definição de políticas públicas, de um discurso de revalorização do meio rural, que antes era negligenciado nas ações de desenvolvimento regional, basicamente voltadas para a estruturação dos espaços urbanos. Esta revalorização se deu com base em dois importantes postulados. O primeiro deles referese ao caráter multifuncional que a agricultura familiar estabelece com o território, sobre o qual o meio rural deixa de ser entendido somente por suas características produtivas e passa a ser valorizado também por seus aspectos sociais, culturais e ambientais, embora a atividade produtiva agropecuária permaneça como atividade nuclear de seu espaço (MALUF, 2001). Para esse segmento sócio produtivo, que se representa de modo diferenciado no território nacional, as propriedades rurais familiares, formando as comunidades rurais, não são apenas lócus de produção, como no caso das grandes propriedades agrícolas empresariais, mas também a base geográfica da vivência, da formação de laços de solidariedade, da reprodução cultural e de todos os fatores materiais e simbólicos que ratificam uma identidade própria (SOUZA, SILVA; SILVA, 2012).

O segundo ponto está relacionado a um posicionamento contrário à dicotomia ruralurbano, que negligencia as relações sociais desenvolvidas na prática em decorrência dos diversos mecanismos de integração entre estes espaços (ABRAMOVAY, 2003). Neste entendimento, rural e urbano são consideradas categorias espaciais que guardam em si especificidades próprias, mas também possuem elos que determinam e são determinadas por suas interações sociais, culturais, políticas e econômicas. Esta interligação entre espaços com características distintas é denominada por Favareto (2007, p. 22) "dinâmicas territoriais de desenvolvimento". Para uma intervenção sobre estas dinâmicas, há a necessidade de entender as articulações entre suas formas de produção e as características morfológicas dos tecidos sociais locais, a partir do entendimento de suas relações de oposição e complementaridade.

No entanto, a adoção de estratégias de intervenção governamental que levem em consideração as dinâmicas territoriais somente foi possível devido a dois fatores em especial, essenciais neste processo: $i$ ) o início de um processo de descentralização política que resultou em maior importância para os poderes administrativos locais (estaduais e municipais) na operacionalização de políticas públicas nacionais; e ii) a introdução de mecanismos institucionais de participação social na definição das ações governamentais nas diferentes esferas administrativas.

Por fim, há de se ressaltar que os processos de planejamento e avaliação de políticas públicas levam em conta ainda alguns fatores que irão diferenciá-las entre si. Por um lado, 
elas se diferenciam em relação a sua matéria de tratamento (educação, saneamento, saúde, habitação), que a definirá enquanto uma política setorial específica. Por outro, as políticas se diferem pelo âmbito de sua cobertura, a ser definida pelos gestores e organismos responsáveis, sobretudo quanto ao público a ser envolvido, os critérios de inclusão e, em alguns casos, também as localidades específicas para sua execução. Assim, a abordagem territorial para o planejamento de políticas públicas auxilia no entendimento dos fenômenos sociais, contextos institucionais e cenários ambientais nos quais ocorrerá a intervenção desejada, de maneira a propiciar meios mais acurados para a definição de diagnósticos e o alcance de metas, parcerias necessárias e instrumentos de implementação.

\section{ANÁLISE INSTITUCIONAL DOS CONSADS}

A implementação dos Consórcios de Segurança Alimentar e Desenvolvimento Local (CONSADs) surgiu em 2003, no âmbito de uma estratégia do governo federal para combater a fome e promover a segurança alimentar no país, ${ }^{2}$ que foi o programa Fome Zero. Além de incorporar ações de curto e longo prazo, este programa também se baseava em estratégias em curso da própria sociedade civil, algumas inclusive passando a ser apoiadas e financiadas pelo Estado.

A temática da segurança alimentar ganhou um papel tão central no governo que, inicialmente, foi criada uma pasta ministerial específica para gerir as ações, o Ministério Extraordinário da Segurança Alimentar, com a sugestiva sigla MESA. Posteriormente, o programa ficou sob a responsabilidade do Ministério do Desenvolvimento Social (MDS), criado para substituir o MESA, sendo operacionalizado pela Secretaria Nacional de Segurança Alimentar e Nutricional (Sesan).

O órgão máximo de articulação da governança dos programas de combate à fome é o Conselho Nacional de Segurança Alimentar e Nutricional (Consea), formado por representantes de governo e sociedade civil. Ele foi originalmente criado em 1993, no governo Itamar Franco, atendendo a uma mobilização social de amplos setores da sociedade brasileira para uma maior ênfase nas ações de combate à fome e à pobreza, sob a liderança do

\footnotetext{
2. O conceito de segurança alimentar atualmente em vigor no Brasil foi definido pela Lei no 11.346 , de 15 de setembro de 2006, que criou o Sistema Nacional de Segurança Alimentar e Nutricional (Sisan). Conhecida como Lei Orgânica da Segurança Alimentar (Losan), em seu artigo terceiro ela estabelece que "A segurança alimentar e nutricional consiste na realização do direito de todos ao acesso regular e permanente a alimentos de qualidade, em quantidade suficiente, sem comprometer o acesso a outras necessidades essenciais, tendo como base práticas alimentares promotoras de saúde que respeitem a diversidade cultural e que sejam ambiental, cultural, econômica e socialmente sustentáveis" (KARAM, 2012, p. 128).
} 
sociólogo Herbert de Souza, o Betinho. Porém, logo em 1995, já no governo de FHC, o Consea, foi extinto. Foi então substituído por uma nova estratégia de combate à pobreza, o Programa Comunidade Solidária (PCS), e suas atribuições foram absorvidas pelo conselho do novo programa (SILVA, 2014).

De acordo com Fiorentim (2012, p. 76), o PCS possuía um perfil eminentemente assistencialista. Os municípios recebiam cestas básicas vindas de fora do município, o que não ajudava a inserir os agricultores locais na comercialização, "como foi possível perceber no Nordeste brasileiro em épocas de seca e em períodos eleitorais". Além disso, este e outros programas assistencialistas em curso na época encontravam-se fragmentados na estrutura governamental. Suas atribuições e operacionalização não recaíam sobre um órgão governamental específico que se responsabilizasse pela condução de tais políticas. Em 1999 ocorreu uma reorientação programática nas políticas sociais, com a substituição do PCS pelo Programa Comunidade Ativa (PCA). No entanto, com a falta de ações mais contundentes no que tange a recursos e estruturas por parte do governo federal, que delegava as responsabilidades ao setor privado e aos governos subnacionais, não foi possível atingir resultados expressivos.

Em 2003, já no governo do presidente Lula, tomou-se a decisão de definir um novo desenho programático para trazer novamente à agenda governamental a temática da segurança alimentar. Foi então que surgiu o programa Fome Zero como uma das principais marcas do novo governo, tendo suas prioridades e ações subordinadas ao Consea, recriado logo no primeiro ano de governo.

No âmbito do programa Fome Zero foram criadas ou inseridas várias políticas que tinham como foco a garantia da segurança alimentar e o combate à pobreza. Entre elas, destaca-se o programa Bolsa Família, criado para ser uma ação única do governo federal de transferência de renda a famílias pobres em todo o Brasil. Outro programa importante foi o Programa Nacional de Fortalecimento da Agricultura Familiar (PRONAF), que, embora já existisse desde 1996, passou a ter uma importância maior com o novo governo, inclusive com aumentos substanciais de recursos disponibilizados e inserção de novas linhas de crédito para maior acesso por parte de agricultores familiares pobres (SILVA, 2011).

Como esses programas eram extensivos a todo o território nacional, sem definição de regiões prioritárias para sua incidência, surgiu a necessidade de se elaborar uma estratégia de articulação entre municípios que apresentassem maiores carências sociais e maiores indicadores de pobreza. Nesse contexto, surgiu a proposta dos CONSADs, planejados 
enquanto arranjos territoriais em regiões de baixo índice de desenvolvimento. Seu objetivo era promover a cooperação entre os municípios nestas condições que possuíam relação de proximidade e identidade geográfica.

Os CONSADs teriam a incumbência de criar um ambiente mais cooperativo para um arranjo territorial institucionalmente formalizado para desenvolver ações, diagnósticos e projetos de segurança alimentar e nutricional e desenvolvimento local, com geração de trabalho e renda, condição fundamental para a saída da pobreza. Seu enfoque territorial baseia-se na construção de uma institucionalidade capaz de mediar conflitos, agregar esforços e gerar sinergias, de forma a direcionar o processo de integração territorial para os objetivos de segurança alimentar e nutricional e desenvolvimento local. Para isso, teria como principais instrumentos as políticas governamentais em torno dessa temática no país.

Essa estratégia configurava um desejo do governo federal de estabelecer uma articulação entre poder público e sociedade civil para viabilizar iniciativas territoriais de desenvolvimento diferenciadas em cada contexto local específico, visando, sobretudo, ao conjunto da população em situação de pobreza e insegurança alimentar. A proposta leva em conta aspectos como: a dimensão física e ambiental e as identidades sociais do território; as relações comerciais, produtivas, políticas e culturais existentes; as potencialidades geoestratégicas para arranjos socioprodutivos sustentáveis; e a reorganização do território visando à inclusão social.

Para viabilizar esses objetivos, os municípios em áreas de CONSADs deveriam ser priorizados para fins de investimento público em políticas sociais por parte de setores do governo federal responsáveis, inclusive com editais específicos para eles. A esta nova estrutura engendrada pelo governo caberia a delicada missão de promover a articulação entre políticas e programas afetos à produção alimentar, à alimentação e à nutrição nos três níveis de governo, agregando também as ações da sociedade civil.

Essa articulação federativa seria operacionalizada por meio de convênios celebrados entre a União e estados ou municípios. Com isso, suas estratégias de intervenção se baseavam em três linhas principais: $i$ ) implementação de ações e políticas específicas de segurança alimentar; ii) articulação de iniciativas de competência de outras esferas de governo e instituições da sociedade civil; e iii) gestão participativa com vistas a tornar as comunidades protagonistas de seu processo de emancipação.

Para detectar melhor como se manifesta regionalmente no país o fenômeno da deficiência nutricional alimentar (ou insegurança alimentar), foi realizado, em 2004, um 
suplemento da Pesquisa Nacional por Amostra de Domicílios (PNAD) do IBGE. Nos termos desta pesquisa, os domicílios brasileiros foram classificados de acordo com quatro categorias de condição de segurança alimentar: segurança alimentar, insegurança alimentar leve, insegurança alimentar moderada e insegurança alimentar grave. ${ }^{3}$ De posse dos resultados, estimou-se que cerca de $35 \%$ dos domicílios brasileiros apresentavam algum tipo de insegurança alimentar. Em todas as regiões havia um número significativo de domicílios nessa situação, sendo as regiões Nordeste e Norte as que possuíam os piores cenários, como demonstra o gráfico 1 a seguir.

Gráfico 1. Situação de segurança alimentar em domicílios particulares por região (2004) - (Em \%)

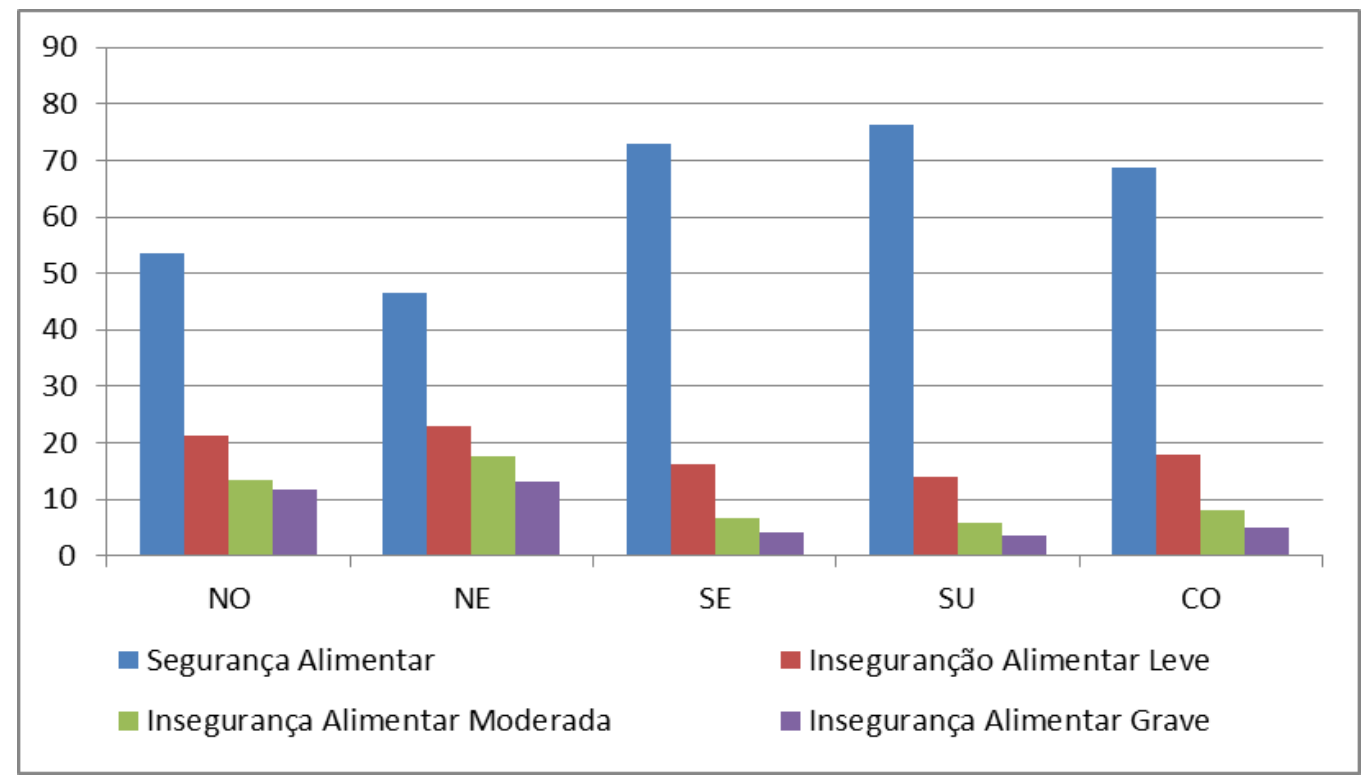

Fonte: IBGE (2004). Elaboração própria.

Essas informações foram muito importantes tanto para balizar a focalização da ação governamental no território nacional, como para justificar o surgimento de novos institutos normativos para regular e comprometer a ação do Estado com essa temática. Entre eles está a aprovação da Lei nº 6.047/2005, conhecida como Lei Orgânica de Segurança Alimentar e Nutricional (Losan). Ela determinou a criação do Sistema Nacional de Segurança Alimentar e

\footnotetext{
3. Segurança alimentar: ocorre quando não há problema de acesso aos alimentos em termos qualitativos ou quantitativos e não há preocupação de que os alimentos venham a faltar. Insegurança alimentar leve: ocorre quando há preocupação com a falta de alimentos no futuro próximo e quando ocorrem arranjos domésticos para que os alimentos durem mais. Insegurança alimentar moderada: ocorrem quando há comprometimento da qualidade da alimentação, buscando-se manter a quantidade necessária. Neste nível de insegurança, inicia-se a redução da quantidade de alimentos entre os adultos. Insegurança alimentar grave: ocorre quando há restrição da quantidade de alimentos, levando à situação de fome entre adultos e crianças.
} 
Nutricional (Sisan), com vistas a assegurar o direito humano à alimentação adequada. ${ }^{4}$ Com isso, a nova lei cumpriu a principal determinação da II Conferência Nacional de Segurança Alimentar e Nutricional, ocorrida na cidade de Olinda, em 2005. O Sisan foi criado para fazer conexões com os sistemas estaduais e municipais a serem construídos pelos entes federados, contribuindo para suprir a pouca capilaridade que o MDS possui nos estados e municípios (FIORENTIM, 2012).

O marco teórico e o modelo de gestão dos consórcios foram definidos em 2004, após a elaboração do documento intitulado Guia do CONSAD. ${ }^{5}$ Com base neste material e em outras propostas debatidas com setores da sociedade, foram mapeados 62 potenciais CONSADs. Desse conjunto mapeado, foram constituídos oficialmente pelo MDS um total de 40, que envolvem 585 municípios e uma população de aproximadamente 11 milhões de habitantes. A seleção dos territórios de CONSADs foi realizada a partir de um amplo diagnóstico denominado Localização de potenciais consórcios de segurança alimentar e desenvolvimento local, realizado pelo Instituto Brasileiro de Administração Municipal (IBAM), visando definir as áreas prioritárias para investimento público em segurança alimentar e apoio ao desenvolvimento local (LTEIF, 2010).

Além dos critérios socioeconômicos, ambientais e culturais para a definição dos territórios potenciais, alguns critérios de distribuição regional também foram estabelecidos, tais como: $i)$ deveria ser constituído um CONSAD em cada um dos estados da União, totalizando 26; e ii) outros 14 CONSADs deveriam ser interestaduais, instituídos para o atendimento das regiões Norte e Nordeste, e formados pelos municípios que possuíam, na ocasião, o maior número de beneficiários do cartão-alimentação do programa Fome Zero e por aqueles localizados em mesorregiões diferenciadas do Ministério da Integração Nacional (ANDREOLLA, 2011).

Os critérios de seleção dos municípios pelo MDS foram definidos com base no perfil socioeconômico, destacando-se também as carências infraestruturais e a presença de agricultura familiar nos municípios. Seu enfoque territorial abrange as seguintes dimensões: $i$ ) as relações sociais, comerciais, produtivas, políticas e culturais existentes na região; ii) a dimensão física e ambiental do território; $i i i)$ as potencialidades geoestratégicas do território

\footnotetext{
${ }^{4}$. Outra conquista institucional importante veio com a EC no 64 de fevereiro de 2010, que alterou o Artigo 6o da CF, introduzindo a alimentação no rol dos direitos fundamentais da população brasileira (D'ÁVILA; SILVA, 2011).

${ }^{5}$. A proposta final foi debatida em grande seminário realizado pelo Mesa em 31 de junho e 1o de julho de 2003 em Brasília, contando com a participação de representantes governamentais (federais e estaduais) e não governamentais de quase todos os estados brasileiros (KARAM, 2012).
} 
como base dos arranjos socioprodutivos sustentáveis; $i v$ ) a necessidade de reorganização do território de forma a proporcionar a inclusão social; v) a construção de uma institucionalidade capaz de mediar conflitos, agregar esforços e gerar sinergias, de forma a direcionar o processo de integração territorial para os objetivos de segurança alimentar e nutricional e desenvolvimento local; e vi) o fortalecimento da identidade territorial e a construção de um sentimento de solidariedade social (JESUS, 2006, p. 62). A distribuição dos CONSADs no território nacional pode ser conferida na figura a seguir.

Figura 1. Localização dos territórios de CONSADs (2004)

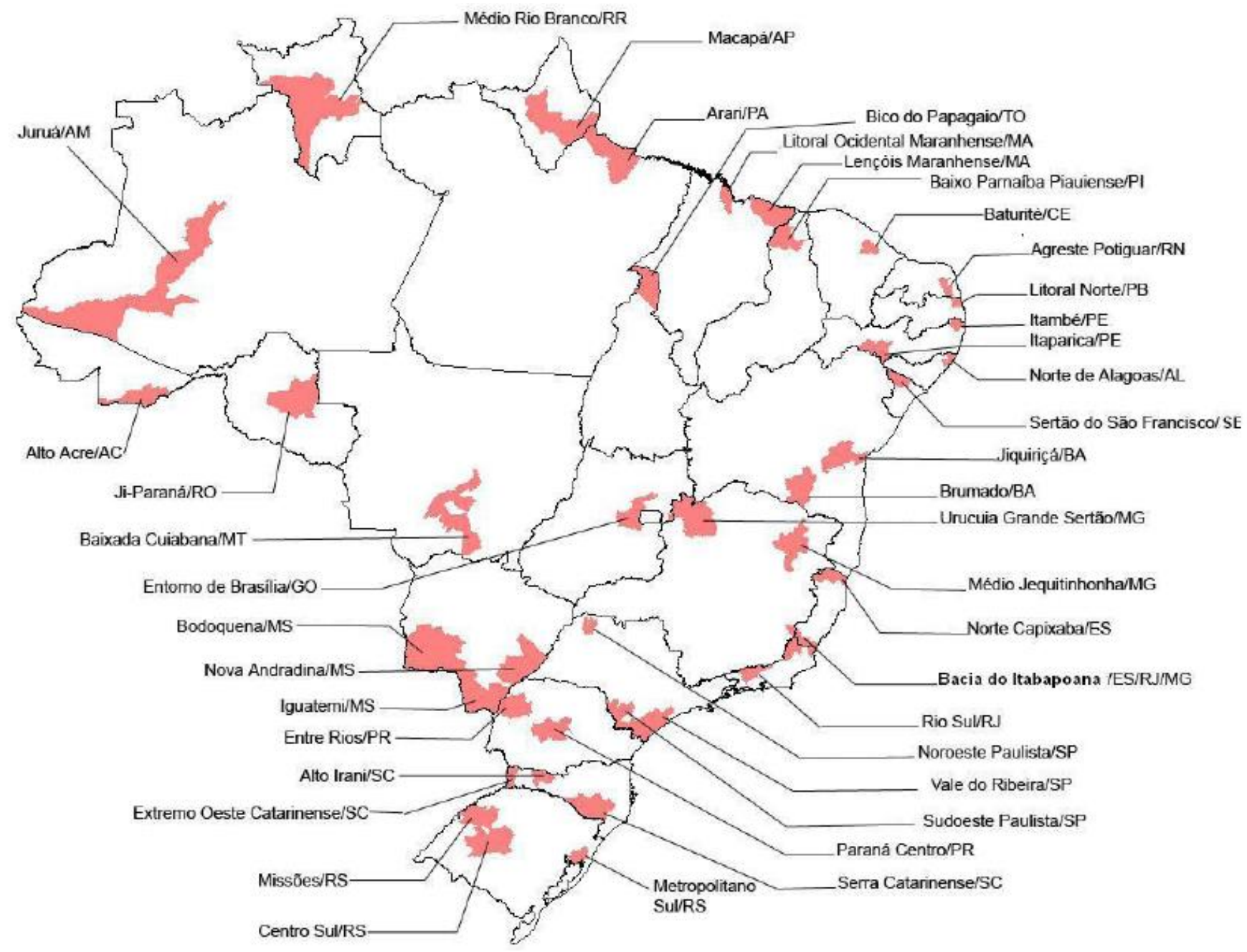

Fonte: Lteif (2010).

Na perspectiva dos CONSADs, o território é entendido como o espaço estratégico fundamental para desenvolver políticas de segurança alimentar de forma intermunicipal e, ao mesmo tempo, construir projetos e ações que integrem as dimensões política, econômica, social e ambiental. Para Fiorentim (2012, p. 50): 
A projeção do futuro para um projeto de desenvolvimento territorial depende do conjunto de relações e interações de uma rede local de sujeitos individuais e coletivos, que pertencem às esferas públicas ou privadas e que estabelecem relações de proximidade e reciprocidade dentro do território para gerar o desenvolvimento local. O desenvolvimento local aqui apresentado refere-se a escalas mais amplas que as fronteiras do município; envolve um conjunto de municípios que apresentam características de proximidade física, confiança e experiências comuns de contexto territorial.

Portanto, os CONSADs são concebidos como uma associação intermunicipal com o objetivo de congregar objetivos sociais do poder público e da sociedade civil para a promoção de ações conjuntas, com foco na segurança alimentar e no desenvolvimento sustentável. Constituem-se em uma forma de associação entre municípios, com espaços instituídos para a participação da sociedade civil e do poder público, para ações conjuntas de geração de emprego e renda. No entendimento de Ortega et al. (2009, p. 5):

\begin{abstract}
A ação consorciada parte da proposta de que a integração territorial é fundamental para melhorar as condições de inserção dos municípios empobrecidos e de pequeno porte na dinâmica do território nacional, provendo essas localidades de melhores condições de competitividade, solidariedade sistêmica e de maiores possibilidades para assegurarem o atendimento às necessidades básicas de seus munícipes. Por intermédio dos consórcios, pretende-se tornar permanente a articulação entre o poder público e a sociedade civil para a promoção de ações de desenvolvimento de forma institucionalizada.
\end{abstract}

A formação de consórcios públicos foi o caminho inicialmente vislumbrado pelos CONSADs, favorecido com a promulgação da Lei $\mathrm{n}^{-}$11.107/2005, que possibilitou a constituição de consórcios intermunicipais (ou entre estados e municípios) com personalidade jurídica de direito público ou privado, no intuito de permitir a construção de novas relações horizontais cooperativas no âmbito regional.

Almejou-se com esta lei facilitar a gestão pública em pequenos municípios e permitir que eles trabalhem em parceria, visando assim aperfeiçoar e potencializar suas capacidades técnica, gerencial e financeira, bem como permitir a assinatura de convênios de forma direta com outras entidades de governo. ${ }^{6}$ A vantagem residiria, portanto, em fornecer aos entes públicos consorciados maior legitimidade jurídica para estabelecer contratos e convênios com o governo federal, corrigindo a situação de fragilidade que havia nos antigos consórcios administrativos. Esperava-se que, com a migração para esta nova institucionalidade, os CONSADs passassem a ser "uma espécie da autarquia, com a finalidade de realizar objetivos de interesse comum entre os entes federativos que o instituíram, podendo ser um instrumento de cooperação federativa no formato horizontal ou vertical" (FIORENTIM, 2012, p. 96). Porém, os próprios CONSADs refletem esta dificuldade, visto que apenas oito consórcios,

\footnotetext{
${ }^{6}$. Os consórcios públicos não se restringem a parcerias intermunicipais. Podem também se efetuados na forma estado-município e União-estados.
} 
dos quarenta planejados inicialmente, se institucionalizaram enquanto consórcios públicos. Segundo Silva (2013b), além de ser um instrumento ainda pouco utilizado para constituir novas institucionalidades capazes de protagonizar ações intermunicipais de desenvolvimento, os consórcios públicos, por serem pessoas jurídicas formadas exclusivamente por entes da Federação, dependem diretamente dos interesses dos governantes eleitos, o que implica os mesmos problemas anteriores à própria lei.

Além disso, uma das críticas mais frequentes à LC remete-se à regra imposta em seu regulamento que exige a regularidade fiscal de todos os entes consorciados para a assinatura de um convênio que estabeleça transferência de recursos da União ao consórcio. Uma regra como esta impõe um sério constrangimento à proliferação de consórcios, uma vez que um único município pode inviabilizar a possibilidade de repasse de recursos de toda uma região.

Dentro da estratégia dos CONSADs, cada território estaria incumbido de buscar o enfrentamento dos problemas de sua região e a alavancagem das potencialidades de cada um dos municípios de maneira articulada, reunidos por laços de identidades sociais, culturais, ambientais e econômicas. Desses municípios são escolhidos os membros que irão compor o Fórum do CONSAD, instância máxima deliberativa dentro do consórcio e responsável por suas decisões políticas.

Os agentes envolvidos têm a incumbência de promover uma articulação para a elaboração de um plano intermunicipal de desenvolvimento sustentável, baseado em um diagnóstico dos principais problemas e das potencialidades econômicas dos municípios.

Além disso, cada fórum deve respeitar dois pressupostos básicos: i) refletir a pluralidade entre os múltiplos segmentos sociais existentes no território; e ii) garantir uma representação majoritária da sociedade civil - equivalente a dois terços dos membros -, no intuito de manter um equilíbrio decisional e estimular a organização social do território como protagonista nas decisões diversas.

Para orientar os fóruns dos CONSADs no processo de gestão social de seus territórios, o MDS preparou uma série de questões orientadoras, resumidas no quadro 1 .

Quadro 1 - Questões orientadoras para a gestão social nos CONSADs

\begin{tabular}{|c|l|}
\hline $\begin{array}{c}\text { Perguntas } \\
\text { orientadoras }\end{array}$ & \multicolumn{1}{c|}{ Problematização do modelo de gestão do desenvolvimento territorial } \\
\hline $\begin{array}{c}\text { Como o CONSAD se } \\
\text { materializa em termos } \\
\text { de uma nova } \\
\begin{array}{c}\text { institucionalidade de } \\
\text { modelo de gestão } \\
\text { territorial? }\end{array}\end{array}$ & $\begin{array}{l}\text { Em uma associação entre municípios de um mesmo território, englobando sociedade } \\
\text { civil e poder público, provida de instrumentos de interlocução política, de tomada de } \\
\text { decisão colegiada, bem como de operacionalização das ações pactuadas, mediante a } \\
\text { promoção de projetos, apoio técnico e aval institucional na obtenção de recursos junto } \\
\text { a parceiros estaduais, nacionais e internacionais. }\end{array}$ \\
\hline
\end{tabular}




\begin{tabular}{|c|c|}
\hline $\begin{array}{c}\text { Quais os seus } \\
\text { objetivos declarados? }\end{array}$ & $\begin{array}{l}\text { Realizar a permanente articulação entre os órgãos públicos e privados, com o objetivo } \\
\text { de estimular o desenvolvimento local, colocando em prática uma série de projetos que, } \\
\text { além de promoverem a segurança alimentar e nutricional, estimulam condições de } \\
\text { produção de alimentos, abastecimento, comercialização e consumo, gerando o } \\
\text { desenvolvimento territorial nos municípios envolvidos. }\end{array}$ \\
\hline $\begin{array}{l}\text { Qual o conceito de } \\
\text { desenvolvimento } \\
\text { territorial que carrega } \\
\text { consigo? }\end{array}$ & $\begin{array}{l}\text { Desenvolvimento territorial consiste em uma concepção de desenvolvimento que une } \\
\text { o equilíbrio territorial, o desenvolvimento endógeno e o desenvolvimento sustentável. } \\
\text { Equilíbrio territorial consiste em que cada parte predefinida de um dado território } \\
\text { conte com as dotações que possibilitam igualdade de oportunidades de todos os } \\
\text { habitantes no que tange ao acesso a bens e serviços básicos, buscando eliminar o } \\
\text { desequilíbrio territorial - ou seja, desigualdades de riqueza e acesso entre diferentes } \\
\text { territórios. Por desenvolvimento endógeno entende-se um processo de } \\
\text { desenvolvimento baseado nas potencialidades locais e na utilização racional destes } \\
\text { recursos. Finalmente, o desenvolvimento sustentável considera as especificidades } \\
\text { ecossistêmicas de um dado território na formulação de estratégias de utilização de } \\
\text { recursos sem afetar as condições de acesso a estes recursos por parte de gerações } \\
\text { futuras. }\end{array}$ \\
\hline $\begin{array}{l}\text { Qual o modelo de } \\
\text { gestão territorial que } \\
\text { propõe? }\end{array}$ & $\begin{array}{l}\text { O modelo de gestão do CONSAD é um processo cíclico que assegura a participação e } \\
\text { tem o caráter de instrumento de negociação e de articulação política com os atores } \\
\text { institucionais e potenciais parceiros, buscando fomentar o empoderamento dos atores } \\
\text { locais e garantir a transparência e rastreabilidade das ações através do monitoramento } \\
\text { e avaliação. }\end{array}$ \\
\hline $\begin{array}{c}\text { Qual a estrutura de } \\
\text { gestão do CONSAD? }\end{array}$ & $\begin{array}{l}\text { Gestão centrada num órgão de deliberação máxima, com participação de dois terços de } \\
\text { representantes da sociedade civil e um terço do poder público local, denominado } \\
\text { Fórum CONSAD, e em órgãos de nível decisório gerencial e operacional. }\end{array}$ \\
\hline $\begin{array}{l}\text { Quais os principais } \\
\text { instrumentos de } \\
\text { implantação local do } \\
\text { CONSAD? }\end{array}$ & $\begin{array}{l}\text { O Guia do CONSAD, apresentado pelo MDS em } 2004 \text {, é o principal instrumento para } \\
\text { a implementação local. Seu objetivo é orientar o processo de implementação em } \\
\text { conformidade com suas premissas, objetivos e metodologia, permitindo a construção } \\
\text { de um referencial comum mínimo de organização e funcionamento para os } \\
\text { CONSADs. }\end{array}$ \\
\hline $\begin{array}{c}\text { Que novas relações de } \\
\text { poder ele propõe? }\end{array}$ & $\begin{array}{l}\text { O CONSAD inaugura uma nova instância de poder decisório microrregional, com } \\
\text { participação majoritária da sociedade civil, minimizando o poder político local } \\
\text { tradicional, sustentado em ações clientelistas e municipalizadas. }\end{array}$ \\
\hline
\end{tabular}

Fonte: Andreolla (2011).

Portanto, a abordagem territorial dos CONSADs surgiu no intuito de estabelecer novas relações federativas para o combate ao problema da insegurança alimentar de uma maneira diferenciada daquela convencional, que até então consistia em meramente ampliar a produção de alimentos sem garantir mecanismos de distribuição de renda no plano local. Caberia então ao governo federal disponibilizar uma série de programas que auxiliassem o processo de desenvolvimento nos territórios dos CONSADs.

Sob esta perspectiva, tomou-se a decisão de investir no mercado interno de produção e comercialização de alimentos, com a descentralização da produção nas regiões e entre regiões, incentivando a formação de articulações intermunicipais em regiões onde se verificam as maiores necessidades, com vistas a potencializar os resultados da ação pública. 
Foi nesse contexto que o governo federal instituiu o Programa de Aquisição de Alimentos (PAA), por meio da Lei no 10.696 , de 2 de julho de 2003. O PAA trouxe em seu desenho institucional uma série de inovações importantes que justificam uma análise mais detalhada de seu processo de implementação e sua importância para a estratégia dos CONSADs. Este programa permite a compra pública de produtos de agricultores familiares, a preços estabelecidos pela Companhia Nacional de Abastecimento (CONAB), para doação, merenda escolar ou formação de estoques. Suas diretrizes foram definidas no Consea e se referiam a dois pontos básicos: $i$ ) aquisição de alimentos diretamente ao segmento familiar; e ii) disponibilização desta oferta de alimentos para atender, de diferentes formas, à demanda adicional por alimentos criada pelas subvenções ao consumo do programa Fome Zero.

Com isso, o PAA vislumbra o fortalecimento tanto da agricultura familiar comercialização e produção para autoconsumo - como da população em estado de insegurança alimentar e de fome no município, população está presente em grande número nos territórios de CONSADs. Os grupos de beneficiários do programa são compostos por agricultores familiares e assentados da reforma agrária, do lado da oferta, e por pessoas que dependem de programas e entidades sociais beneficentes, pelo lado da demanda. Seu objetivo, portanto, é promover a articulação entre a produção da agricultura familiar e a destinação desta produção, visando ao desenvolvimento da economia local e ao atendimento direto às demandas de suplementação alimentar e nutricional dos programas sociais locais (ORTEGA, 2007).

Uma mudança institucional fundamental para a viabilização do PAA foi a dispensa dos processos licitatórios para compras públicas, requeridos pela Lei $n^{-0}$ 8.666/1993, na aquisição de produtos da agricultura familiar para fins do programa, desburocratizando o processo de comercialização. Esta inovação institucional propiciou uma atuação diferenciada do Estado para atuar proativamente nas economias de territórios de baixa dinamização econômica e forte presença de agricultores familiares. Os CONSADs passaram a ser regiões prioritárias para a efetivação dos investimentos do PAA.

Os preços dos produtos adquiridos pela CONAB são definidos em relação à média dos preços praticados nos mercados regionais. O limite de aquisições é definido por decreto, estabelecendo-se anualmente um valor máximo por família. São quatro as modalidades operacionais do programa: i) compra direta da agricultura familiar; ii) formação de estoques pela agricultura familiar; iii) compra direta para doação simultânea; e $i v$ ) incentivo à produção e ao consumo do leite. 
Em seus primeiros oito anos de operacionalização (2003-2011), o PAA atendeu mais de 700 mil famílias agricultoras em todas as UFs, investindo um total superior a $\mathrm{R} \$ 2,2$ bilhões e beneficiando mais de 20 milhões de pessoas em situação de insegurança alimentar.

A região Sul obteve ao longo deste período o maior volume de recursos e famílias atendidas pelo PAA. Entre os fatores que determinaram este predomínio foi o surgimento da linha de formação de estoque pela agricultura familiar, em 2006, com recursos do Ministério do Desenvolvimento Agrário (MDA), que propiciou uma elevação brusca na participação percentual do Sul em relação ao total dos recursos do PAA. A região respondeu por mais de $70 \%$ da execução dos valores desta linha.

Uma explicação para esse fato é a existência na região de um sistema de agroindústrias familiares mais desenvolvido e formalizado. Outro fator é a maior articulação de agricultores familiares e suas organizações, que permitiu um arranjo territorial mais propício para a incidência desta política pública, promovendo melhores formas de acesso dos agricultores a este mercado institucional ${ }^{7}$ importante para a atividade agrícola familiar (VOGT, 2008).

Por sua vez, nos anos mais recentes, as demais regiões vêm conseguindo aumentar sua participação relativa no número de famílias agricultoras beneficiadas pelo PAA. Para uma análise regional, a tabela 1 mostra a evolução relativa recente entre cada uma das regiões quanto ao montante de recursos financiados do PAA entre os anos de 2003 a 2010. Já o gráfico 2 apresenta a participação total de cada região nos recursos do PAA no agregado do período.

Tabela 1 - Evolução dos investimentos do PAA por região, 2003-2011 (Em R\$)

\begin{tabular}{ccccccr}
\hline \multirow{2}{*}{ Ano/região } & Norte & Nordeste & Sudeste & Sul & $\begin{array}{c}\text { Centro- } \\
\text { Oeste }\end{array}$ & Total \\
\hline 2003 & 8.194 .157 & 31.672 .408 & 7.603 .665 & 17.639 .249 & 16.431 .728 & $\mathbf{8 1 . 5 4 1 . 2 0 7}$ \\
2004 & 28.391 .528 & 42.307 .978 & 8.903 .396 & 24.196 .831 & 3.386 .094 & $\mathbf{1 0 7 . 1 8 5 . 8 2 7}$ \\
2005 & 16.149 .222 & 34.745 .917 & 13.876 .678 & 42.481 .492 & 5.538 .352 & $\mathbf{1 1 2 . 7 9 1 . 6 6 1}$ \\
2006 & 17.826 .019 & 55.113 .452 & 32.460 .597 & 85.459 .203 & 10.095 .309 & $\mathbf{2 0 0 . 9 5 4 . 5 8 0}$ \\
2007 & 18.799 .858 & 56.116 .348 & 42.080 .964 & 102.648 .844 & 8.706 .954 & $\mathbf{2 2 8 . 3 5 2 . 9 6 8}$ \\
2008 & 15.679 .112 & 80.840 .501 & 73.428 .218 & 96.112 .379 & 9.893 .516 & $\mathbf{2 7 5 . 9 5 3 . 7 2 6}$ \\
2009 & 15.550 .480 & 102.838 .205 & 78.842 .348 & 152.926 .807 & 13.224 .101 & $\mathbf{3 6 3 . 3 8 1 . 9 4 1}$ \\
2010 & 28.348 .787 & 121.858 .906 & 79.151 .714 & 128.975 .115 & 21.400 .943 & $\mathbf{3 7 9 . 7 3 5 . 4 6 5}$ \\
2011 & 29.386 .137 & 153.674 .198 & 111.741 .509 & 124.209 .257 & 32.025 .103 & $\mathbf{4 5 1 . 0 3 6 . 2 0 4}$ \\
\hline Total & $\mathbf{1 7 8 . 3 2 5 . 3 0 0}$ & $\mathbf{6 7 9 . 1 6 7 . 9 1 3}$ & $\mathbf{4 4 8 . 0 8 9 . 0 8 9}$ & $\mathbf{7 7 4 . 6 4 9 . 1 7 7}$ & $\mathbf{1 2 0 . 7 0 2 . 1 0 0}$ & $\mathbf{2 . 2 0 0 . 9 3 3 . 5 7 9}$ \\
\hline
\end{tabular}

Fonte: CONAB. Disponível em: <http://www.conab.gov.br/conteudos.php?a=1402\&t=2>.

\footnotetext{
7. Mercados institucionais são aqueles formados a partir de demandas de produtos e serviços para fins de uso no âmbito das instituições públicas (escolas, creches, hospitais, presídios etc.). Podem envolver as três esferas de governo (municipal, estadual e federal) em todas as suas operações, seja em caráter contínuo, seja esporádico (VOGT, 2008).
} 
Gráfico 2 - Participação total das regiões no financiamento do PAA, 2003-2010. (Em \%)

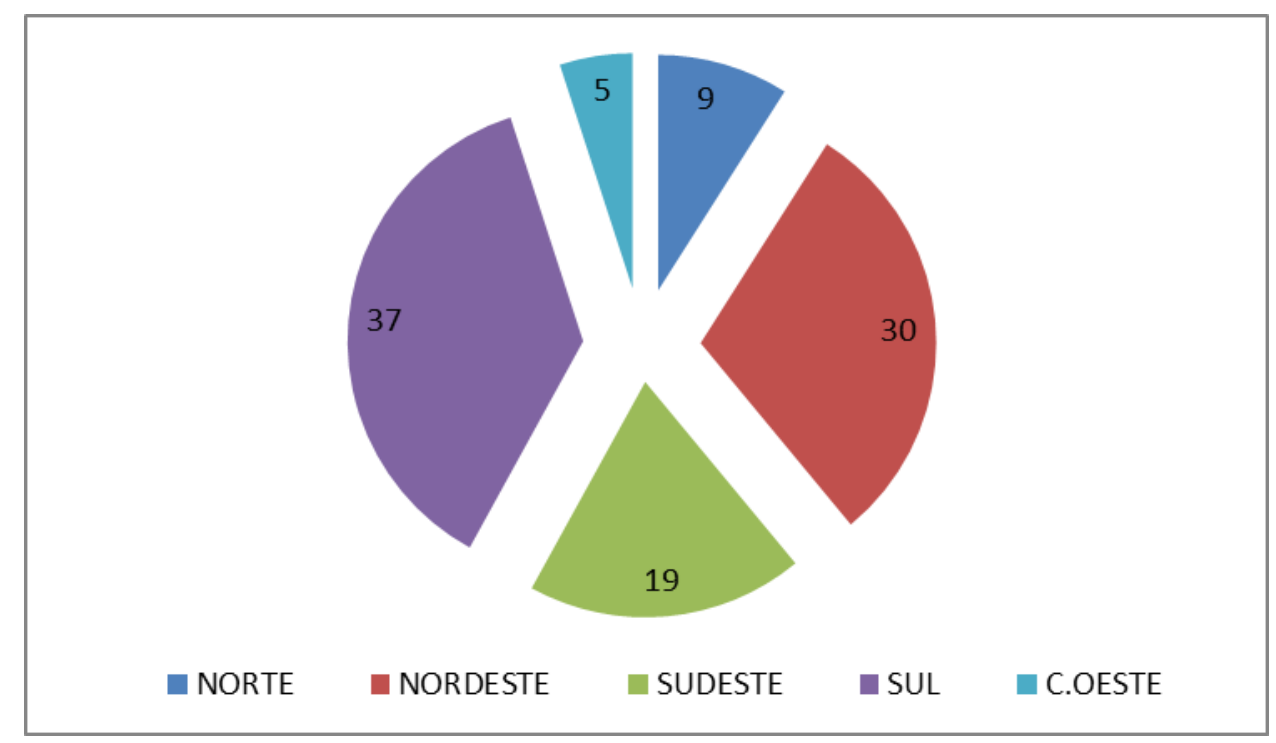

Fonte: CONAB. Disponível em: <http://www.conab.gov.br/conteudos.php?a=1402\&t=2>.

Apesar da evolução dos recursos do PAA ao longo dos anos, os movimentos sociais do campo, que inclusive participam das reuniões do Consea, reclamam que os recursos ainda são insuficientes para atender toda a demanda da agricultura familiar de modo a propiciar novas dinâmicas econômicas territoriais e a garantia da soberania alimentar nos territórios. A falta de uma estrutura mais adequada da CONAB para a operacionalização do programa nos estados é outro ponto que se questiona. Além disso, a falta de assistência técnica, tanto para a elaboração de projetos para a aquisição de produtos quanto para o acompanhamento da atividade produtiva, também é sempre colocada em pauta pelos atores locais, sobretudo nos assentamentos de reforma agrária. Por fim, a burocracia em alguns estados para cumprir todos os requisitos necessários para a contratação, aliada a constantes atrasos no pagamento dos produtos, completa as principais dificuldades de execução do PAA, de acordo com o público beneficiário.

Em 2008 surgiu um novo reforço na constituição de mercados institucionais para a segurança alimentar. A modalidade de aquisição de alimentos para atendimento da alimentação escolar foi incorporada ao PAA por meio da Resolução do Grupo Gestor do Programa de Aquisição de Alimentos (GGPAA)/SESAN/MDS nº 30, de 7 de agosto de 2008. Esta modalidade destina-se a promover a produção de agricultores familiares e a demanda das escolas para atendimento da alimentação escolar. A resolução prevê que o Fundo Nacional para o Desenvolvimento da Educação (FNDE) definirá a sistemática e os procedimentos 
operacionais em relação aos produtos adquiridos, estabelecendo uma porcentagem mínima de $30 \%$ do valor a ser gasto com alimentação escolar para a aquisição de produtos da agricultura familiar local. Além de novos recursos para a comercialização institucional de seus produtos, outra vantagem para os agricultores familiares com esta nova conquista é que a demanda por alimentação escolar é constante, diferentemente do que ocorre no PAA, que apresenta descontinuidades por causa do fluxo de recursos e articulações políticas.

Para além da garantia de comercialização dos produtos de agricultores familiares locais, o PAA também apresenta uma série de aspectos positivos que contribuem, direta e indiretamente, para o desenvolvimento territorial, sobretudo em regiões de baixa dinamização econômica, como no caso dos CONSADs. A recuperação dos preços pagos aos agricultores está entre os benefícios indiretos do PAA. Ao estabelecer um preço médio, o PAA cria naturalmente mecanismos de alocação de recursos em municípios com maior necessidade, onde os preços estão mais defasados (D’ÁVILA; SILVA, 2011).

Portanto, dentro da estratégia pensada para o desenvolvimento dos territórios dos CONSADs, pode-se dizer que o PAA foi o principal programa, não apenas pela quantidade de recursos, mas principalmente pelo seu caráter inovador em propiciar um alinhamento entre políticas de segurança alimentar e desenvolvimento local a partir de recursos e forças produtivas do próprio território. Uma de suas características fundamentais é a importância da participação da sociedade civil para a definição de diretrizes do programa a cada ano, seja por meio do Consea, seja pelas Conferências Nacionais de Segurança Alimentar. Esta participação é fundamental para que novos ajustes possam ser conferidos ao programa periodicamente e ele possa adquirir uma aderência maior aos diferentes contextos territoriais brasileiros. Além disso, garante legitimidade política e social ao programa, para que se possa alcançar o nível de recursos necessários para o atendimento de um número cada vez maior de famílias (SILVA, 2014).

No entanto, a abordagem territorial dos CONSADs vem perdendo claramente sua importância enquanto marca política no interior da estrutura de governo, de modo que ele praticamente não aparece no desenho do Plano Plurianual 2012/2015. Os programas sociais que surgiram em seu entorno ganharam importância própria, com recursos e estruturas específicas, como no caso do próprio PAA. Por outro lado, a consolidação destes programas que compuseram inicialmente a estratégia dos CONSADs pode ser um desdobramento positivo de sua operacionalização. 


\section{CONSIDERAÇÕES FINAIS}

Este trabalho visou analisar o processo de planejamento e implementação dos CONSADs enquanto uma nova abordagem de ação governamental, por meio de políticas públicas com foco em territórios de incidência específicos. Como visto, os CONSADs foram implementados inicialmente em 2003 no âmbito de uma estratégia maior de combate à fome, miséria e para o estímulo ao desenvolvimento local, que era o Programa Fome Zero.

Seu objetivo era constituir arranjos federativos envolvendo municípios com altos índices de pobreza para serem apoiados com diversos programas governamentais, no intuito de dinamizar novas oportunidades de negócio para a dinamização das economias internas. A agricultura familiar foi adotada como um segmento socioprodutivo estratégico para esses projetos, e aos atores sociais (públicos e privados) dos municípios envolvidos ficaria o encargo de constituírem arranjos próprios de governança territorial para acessar as políticas e desenvolver novos projetos e parcerias.

A estratégia dos CONSADs, portanto, apresentou importantes inovações no campo normativo para a análise de implementação de políticas públicas no Brasil. Primeiramente, pelo fato de utilizar-se de escalas alternativas para a pactuação e operacionalização das ações governamentais, ao focar suas ações em territórios e não em municípios isolados.

A abertura para a participação social nos fóruns internos mostrou também que essa política não pretendia ser algo totalmente ditado pelo governo federal. A constituição de conselhos e fóruns de políticas possibilitou que a população residente, por meio de suas organizações sociais, poderiam propor projetos mais condizentes com suas realidades e acompanhar todos os processos de decisão e implementação.

Outro fator importante de inovação a ser destacado nessa estratégia é a forma diferenciada de combate à fome e à insegurança alimentar nas regiões pobres do país. Historicamente esse problema sempre foi tratado de cima para baixo, de maneira clientelista, via distribuição de cestas básicas sem nenhum controle social e nenhum compromisso com a economia local. No caso dos CONSADs, eles estavam inseridos em uma estratégia mais abrangente, cujo objetivo era aproveitar o potencial produtivo nos próprios territórios para a produção de alimentos, gerando novas oportunidades produtivas para as famílias locais.

Nesse ponto, foi fundamental a dispensa dos processos licitatórios para compras públicas, requeridos pela Lei $n^{\circ}$ 8.666/1993, para a aquisição de produtos da agricultura familiar desses municípios, com o lançamento do PAA. Com isso, o programa passou a ter 
dois grupos de beneficiários: os agricultores familiares locais, que passaram a poder acessar um mercado institucional para a comercialização de seus produtos; e as famílias carentes e dependentes de organizações assistenciais, que passaram a receber esses alimentos, produzidos localmente. Posteriormente, a aprovação em 2008 da normativa do FNDE que obrigou a compra por parte dos municípios de no mínimo 30\% de produtos da agricultura familiar para os programas de alimentação escolar municipal permitiu a ampliação desse mercado institucional. O Estado passou a atuar ativamente utilizando seu poder de compra para potencializar atividades produtivas nessas áreas.

No entanto, alguns entraves operacionais ficaram evidentes na implementação desse programa. O principal deles reside na dificuldade que ainda se tem no Brasil em se constituir arranjos federativos voltados a cooperação em torno de projetos comuns. Tanto é verdade que apenas oito dos 40 CONSADs se formalizaram enquanto consórcios públicos. Por um lado, o componente político muitas vezes atrapalha essa aproximação, em nome de velhas disputas internas entre famílias e grupos de interesse locais; por outro, os municípios possuem pouca disponibilidade orçamentária para animar processos de pactuação e organização territorial como previa os CONSADs. Nesse caso, o governo federal também deveria prever recursos adicionais para essa etapa intermediaria, porém de grande importância para o desenvolvimento da estratégia proposta.

Por fim, as análises desse trabalho permitiram dizer que a experiência na implementação dos CONSADs evidenciou uma série de situações e entraves relevantes para uma análise mais detalhada da adoção da abordagem territorial para o planejamento e implementação de políticas públicas no Brasil. É sabido que os processos não avançam de maneira uniforme em todos os territórios, dada a imensa disparidade regional que existe no país. Isso é própria de uma política dessa natureza, e devem ser previstos instrumentos que apoiem de maneira diferenciada territórios em estágios distintos de organização social e produtiva.

Portanto, mesmo com os CONSADs perdendo espaço na agenda governamental após 10 anos de sua implementação, considera-se neste trabalho que ela foi uma ação importante e propiciou dinâmicas inovadoras em frações do território nacional, além de permitir o fortalecimento de políticas hoje consolidadas institucionalmente, como no caso do PAA. 


\section{REFERÊNCIAS}

ABRAMOVAY, Ricardo. O futuro das regiões rurais. Porto Alegre: Ed. UFRGS, 2003.

ANDREOLLA, Elisiane. Avaliando propositivamente a experiência do CONSAD do Extremo Oeste Catarinense como um modelo de gestão do desenvolvimento territorial. 2011. Dissertação (Mestrado) - Universidade Federal da Bahia, Salvador, 2011.

ARAÚJO, Tânia Bacelar. Pensando o futuro das políticas de desenvolvimento territorial no Brasil. In: MIRANDA, Carlos; TIBÚRCIO, Breno. Políticas de desenvolvimento territorial no Brasil: avanços e desafios. Brasília: NEAD, 2010.

BERTONE, Leonor; MELLO, Neli Aparecida. Perspectiva do ordenamento territorial no Brasil: dever constitucional ou apropriação política? In: STEINBERGER, Marília (Org.). Território, ambiente e políticas públicas espaciais. Brasília: Paralelo 15; LGE, 2006.

BRANDÃO, Carlos. Territórios com classes sociais, conflitos, decisão e poder. In: ORTEGA, Antônio; FILHO, Niemeyer (Org.). Desenvolvimento territorial: segurança alimentar e economia solidária. Campinas: Alínea, 2007.

D’ÁVILA, Claudia A. R.; SILVA, Sandro P. Segurança alimentar e desenvolvimento local: uma análise dos resultados do Programa de Aquisição de Alimentos (PAA) em Minas Gerais. Revista de políticas públicas, v. 15, n. 2, 2011.

FAVARETO, Arilson. Paradigmas do desenvolvimento rural em questão. São Paulo: FAPESP, 2007.

FIORENTIN, Marcos. Uma perspectiva de território integrador no CONSAD Extremo Oeste de Santa Catarina. Porto Alegre: UFRGS, 2012. Tese (Doutorado em Geografia). Universidade Federal do Rio Grande do Sul, 2012.

FLIGSTEIN, Neil. Habilidade social e a teoria dos campos. Revista de Administração Pública, vol. 47, $\mathrm{n}^{\circ}$ 2, 2007.

KARAM, Ricardo A. A economia política do desenvolvimento territorial: uma análise da diversidade institucional na agenda brasileira. 2012. Tese (Doutorado) - Universidade Federal do Rio de Janeiro, Rio de Janeiro, 2012.

LTEIF, Ana P. A. S. Abou. Desenvolvimento rural, segurança alimentar e políticas públicas. In: CONGRESSO LATINOAMERICANO DE SOCIOLOGIA RURAL, $8^{\circ}, 2010$, Porto de Galinhas, Pernambuco. Anais... Porto de Galinhas: Alasru, 2010.

MALUF, Renato. Políticas agrícolas e de desenvolvimento rural e a segurança alimentar. In: LEITE, Sérgio (Org.). Políticas públicas e agricultura no Brasil. Porto Alegre: Ed. UFRGS, 2001.

ORTEGA, Antônio C. Desenvolvimento territorial rural no Brasil: limites e potencialidades dos CONSADs. Revista de economia e sociologia rural, v. 45, n. 2, 2007.

ORTEGA, Antônio C. et al. Desenvolvimento territorial rural e consórcios intermunicipais: estudo de caso dos arranjos sócios produtivos induzidos em Minas Gerais. In: CONGRESSO DA SOBER, 47., 2009, Porto Alegre. Anais... Porto Alegre, 2009. 
SILVA, Sandro Pereira. Políticas públicas, agricultura familiar e desenvolvimento territorial. Cadernos gestão pública e cidadania, São Paulo: FGV, v. 16, n. 58, 2011.

. Considerações analíticas e operacionais sobre a abordagem territorial em políticas públicas. In: IPEA. Brasil em Desenvolvimento 2013: Estado, planejamento e políticas públicas (vol. 1). Brasília: IPEA, 2013.

Avanços e limites da implementação de políticas públicas nacionais sob a abordagem territorial no Brasil. Texto de Discussão, nº 1898. Brasília: IPEA, 2013 b.

SOUZA, Emanuel F. M.; SILVA, Marcio G.; SILVA, Sandro Pereira. A cadeia produtiva da mandiocultura no Vale do Jequitinhonha. Revista Isegoria, $\mathbf{n}^{\mathbf{0}}$ 2, 2012.

VOGT, Silmara P. C. A construção social do mercado institucional de alimentos: estudo de caso do Programa de Aquisição de Alimentos na Região de Celeiro - RS. Santa Maria (RS): UFSM, 2008. Dissertação (Mestrado em Extensão Rural). Universidade Federal de Santa Maria, 2008. 